\title{
Lipid Composition of Paracoccidioides brasiliensis: Possible Correlation with Virulence of Different Strains
}

\author{
By M. S. MANOCHA, ${ }^{*}$ G. SAN-BLAS ${ }^{2}$ AND SONIA CENTENO 2 \\ ${ }^{1}$ Department of Biological Sciences, Brock University, \\ St Catharines, Ontario, Canada \\ ${ }^{2}$ Centro de Microbiologia y Biologia Celular, \\ Instituto Venezolano de Investigaciones Cientificas, Caracas, Venezuela
}

(Received 4 July 1979)

\begin{abstract}
The lipid content and composition of four strains of Paracoccidioides brasiliensis were analysed to determine any possible correlation with their virulence for hamsters and mice. Two strains, $\mathrm{Pb} 168$ and $\mathrm{Pb} 141$, were equal in virulence, $\mathrm{Pb} 9$ was slightly virulent and $\mathrm{Pb} 140$ was avirulent under the experimental conditions. No correlation was observed between virulence and the total lipid or phospholipid content of the strains. The lipid yield was highest in $\mathrm{Pb} 9$ and lowest in $\mathrm{Pb} 168$. Polar lipids were highest in $\mathrm{Pb} 9$ and least in $\mathrm{Pb} 140$. Phosphatidylcholine was the dominant phospholipid in all strains but its percentage was lower in the avirulent strain Pbl40. Diphosphatidylglycerol, the least saturated lipid in all strains, was less abundant in $\mathrm{Pb} 140$ than in the virulent strains $\mathrm{Pb} 168$ and $\mathrm{Pb} 141$. In all four strains, neutral lipids constituted the major fraction of total lipids and triglycerides were the predominant individual lipid class, being more abundant in the avirulent and slightly virulent strains than in the virulent strains. The fatty acid profiles of total lipids and individual lipid classes of neutral and polar lipids obtained from the four strains were similar; however, the individual lipid classes showed patterns of preferential distribution of these fatty acids.
\end{abstract}

\section{INTRODUCTION}

Qualitative and quantitative analysis of the lipids in pathogenic fungi and their relationship to virulence has been the subject of several studies. Peck (1947) suggested an association of lipid content with the virulence of pathogenic fungi. Di Salvo \& Denton (1963) studied the lipid contents of four strains of Blastomyces dermatitidis and suggested a positive correlation between the amount of total lipid in each strain and its virulence for mice. Nielsen (1966) investigated the possibility that a similar relationship between lipid content and virulence might also exist in another fungus, Histoplasma capsulatum, causing systemic infection in man. His data suggested that in the six isolates studied neither total extractable lipid nor phospholipid showed a quantitative correlation with virulence. However, the possibility that the quantity of phosphatidylcholine correlates with the virulence of a given isolate of $H$. capsulatum was not ruled out. A possible relationship between phospholipids and virulence of $B$. dermatitidis strains was suggested by Cox \& Best (1972). In an attempt to explain the cause of attenuation of virulence, Anderes et al. (1973) studied the lipids of an auxotrophic avirulent mutant of Coccidioides immitis and compared its lipid composition with that of the wild-type.

Virtually nothing is known about the lipid composition of Paracoccidioides brasiliensis, the causal organism of South American blastomycosis. It was therefore considered profitable 
to undertake an extensive study of the lipid composition of some selected strains of $P$. brasiliensis and to investigate the correlation, if any, which exists between this and their virulence for hamsters and mice. This paper reports the results of such a study.

\section{METHODS}

Fungal strains and cultures. Strains of Paracoccidioides brasiliensis $\mathrm{Pb} 168, \mathrm{~Pb} 141$ and $\mathrm{Pb} 140$ were obtained by treating the yeast form of $P$. brasiliensis $\mathrm{Pb} 9$ of the Instituto Venezolano de Investigaciones Cientificas (IVIC) with $N$-methyl- $N^{\prime}$-nitro- $N$-nitrosoguanidine. The method of their isolation and purification has been described elsewhere (San-Blas \& Centeno, 1977). All strains were grown routinely on a medium consisting of ( $\mathrm{g}^{-1}$ in distilled water): glucose, 20; glycine, 10 ; yeast extract, 5; agar, 15. The $\mathrm{pH}$ of the medium was adjusted to $7 \cdot 2$. The cultures were grown at $37^{\circ} \mathrm{C}$ for 4 to $5 \mathrm{~d}$, i.e. until the mid-exponential phase of growth. Harvested cultures were washed with distilled water and immediately lyophilized.

Virulence tests. Exponentially growing cultures of $P$. brasiliensis strains were washed with distilled water, centrifuged at $2000 \mathrm{~g}$, resuspended in $0.85 \%(\mathrm{w} / \mathrm{v}) \mathrm{NaCl}$ and gently homogenized in a tissue grinder. The concentration of yeast-like cells was adjusted to $2 \times 10^{6}$ colony-forming units $\mathrm{ml}^{-1}$. Adult outbred male hamsters, weighing an average of $90 \mathrm{~g}$, and male white mice (strains NMR1/IVIC and BALB/c), weighing 20 to $25 \mathrm{~g}$, were inoculated intraperitoneally with $1.0 \mathrm{ml}$ cell suspension. Twelve animals of each species were used to test the virulence of each strain of $P$. brasiliensis. Necropsy was not performed on animals dying in the first 2 weeks of the experiment. From the survivors, one animal of each species was sacrificed each month up to 6 months and examined for visible lesions on the viscera and for the presence of paracoccidioidomycotic nodules on the mesenteric and peritoneal surfaces. Portions of whole viscera, removed at autopsy, were macerated and cultured on Mycosel agar (BBL) slants. Yeast colonies that developed on Mycosel agar were transferred and kept on Sabouraud dextrose agar (Difco).

Lipid extraction. The lyophilized cultures were extracted with $20 \mathrm{vol}$. each of chloroform/methanol as $2: 1,1: 1$ and $1: 2(\mathrm{v} / \mathrm{v})$ mixtures. The cultures were suspended in chloroform/methanol $(2: 1, \mathrm{v} / \mathrm{v})$ and homogenized in a Sorvall Omni-Mixer (Ivan Sorvall, U.S.A.) for $1 \mathrm{~h}$. The extract was separated by centrifuging at $5000 \mathrm{~g}$ for $5 \mathrm{~min}$ and the pellet, suspended in chloroform/methanol $(1: 1, \mathrm{v} / \mathrm{v})$, was macerated in a Potter Elvehjem tissue grinder (Fisher Scientific Co., Fairlawn, N.J., U.S.A.). The extract was separated by centrifuging and the pellet was resuspended in chloroform/methanol $(1: 2, \mathrm{v} / \mathrm{v})$ with constant stirring. The combined extracts were reduced to near dryness on a rotary evaporator, taken up in known volume of Folch's lower phase solvent and washed with the upper phase solvent (Folch et al., 1957). The lipid extract in the lower phase was evaporated to a small volume, dried with $\mathrm{Na}_{2} \mathrm{SO}_{4}$ and centrifuged. The supernatant was dried to constant weight, first by a stream of $\mathrm{N}_{2}$ and then under vacuum in a desiccator.

Separation of lipids. Total lipids (100 to $120 \mathrm{mg}$, in $3 \mathrm{ml}$ chloroform) were loaded on to a silicic acid column. Neutral lipids were eluted with chloroform and polar lipids with chloroform/methanol $(1: 1, \mathrm{v} / \mathrm{v})$ followed by methanol. The eluted fractions were reduced to a known volume and samples containing 2 to $3 \mathrm{mg}$ lipid were spotted on heat-activated $20 \times 20 \mathrm{~cm}$ plates coated with $250 \mu$ m thick Kieselgel G (E. Merck, Darmstadt, Germany). Neutral lipids were separated in the single solvent system consisting of hexane/ diethyl ether/acetic acid (85:15:1, by vol.). For two dimensional separation of polar lipids a double solvent system was used. The successive solvent systems were: (1) chloroform/methanol/aqueous $\mathrm{NH}_{4} \mathrm{OH}$ (75:25:3, by vol.); (2) chloroform/methanol/acetic acid/water (170:25:25:4, by vol.). All solvents contained $0.01 \%$ $(\mathrm{w} / \mathrm{v})$ butylated hydroxytoluene to prevent oxidation of the lipids.

Identification and quantitative estimation of lipids. Lipids were visualized by first spraying the plate with $50 \% \mathrm{H}_{2} \mathrm{SO}_{4}$ followed by heating at $90{ }^{\circ} \mathrm{C}$ for 15 to $20 \mathrm{~min}$. They were identified by (i) co-chromatography with standard lipids (Applied Science Laboratories, College Park, Penn., U.S.A.), (ii) comparison of the patterns obtained with published diagrams for these solvent systems (Deven \& Manocha, 1975) and (iii) reactions of specific classes of lipids with various reagents.

For quantitative estimation and fatty acid analysis of individual lipid classes, the plates were sprayed with $0.02 \%(\mathrm{w} / \mathrm{v})$ Rhodamine $6 \mathrm{G}$ and examined under fluorescent light. Visualized spots of lipid were scraped off from 12 to 15 plates and the lipids were eluted from the gel with chloroform/methanol $(2: 1, \mathrm{v} / \mathrm{v})$. The eluted fractions were dried to constant weight and the amount of each individual lipid class was determined gravimetrically. The recovery of lipids was 84 to $86 \%$ in all cases. Calculations are based on $100 \%$ recovery for sake of convenience and comparison between the strains.

Gas-liquid chromatography of fatty acids. Fatty acid methyl esters from various lipid classes were prepared as described by Deven \& Manocha (1975). A gas chromatograph (Varian model 3700; Varian Instrument Division, Palo Alto, Calif., U.S.A.) equipped with a flame ionization detector was used for analysis. A glass column $(180 \mathrm{~cm} \times 2 \mathrm{~mm}$ i.d.), packed with $3 \%$ (w/v) SP-2330 on 100 to 120 Supelcoport, was temperature 
programmed from 120 to $220^{\circ} \mathrm{C}$ at $3{ }^{\circ} \mathrm{C} \mathrm{min-1}$. The injector and detector temperatures were $200{ }^{\circ} \mathrm{C}$ and $300^{\circ} \mathrm{C}$, respectively. Identification of fatty acids was achieved by (i) comparison of retention times with authentic standards and (ii) co-chromatography with known fatty acid samples. Quantitative estimation of the peak areas was made according to the method of Carrol (1961).

\section{RESULTS}

\section{Virulence of P. brasiliensis strains}

The four strains of $P$. brasiliensis used in this study demonstrated a marked difference in their virulence for hamsters and mice. Autopsy performed on all animals infected with any strain, sacrificed in the first and second month, revealed paracoccidioidomycotic nodules of various sizes scattered throughout the mesentery. There was no evidence of infection of the viscera in any of the animals challenged with strain $\mathrm{Pb} 140$. However, mesenteric nodules removed from these animals and stained with a vital stain (Berliner \& Reca, 1966) revealed non-viable, deteriorated yeast-like cells mostly without their cytoplasm. Thus, strain Pb140 proved to be avirulent whereas strains $\mathrm{Pb} 141$ and $\mathrm{Pbl} 68$ were virulent under our laboratory conditions. Lesions containing viable cells of the pathogen were observed in both the hamsters and two strains of mice inoculated with $\mathrm{Pb} 141$ and $\mathrm{Pb} 168$. Inoculation with $\mathrm{Pb}$, a strain of relatively low virulence, led to the development of lesions in the hamster but it did not produce disease and could not be recovered from experimentally infected mice.

\section{Lipid yield and fatty acid composition}

The total lipid yields of $P$. brasiliensis strains were as follows: Pb140, 7.4 to $8.2 \%$; $\mathrm{Pb} 9,9 \cdot 0$ to $9 \cdot 8 \% ; \mathrm{Pb} 141,6 \cdot 3$ to $6.8 \% ; \mathrm{Pb} 168,4.6$ to $5.3 \%$. There was a marked similarity in the fatty acid profiles of total lipids obtained from these strains. The major fatty acids in all the strains were palmitic acid $\left(\mathrm{C}_{16: 0}\right)$, palmitoleic acid $\left(\mathrm{C}_{16: 1}\right)$, stearic acid $\left(\mathrm{C}_{18: 0}\right)$, oleic acid $\left(\mathrm{C}_{18: 1}\right)$ and linoleic acid $\left(\mathrm{C}_{18: 2}\right)$. Oleic acid was present in the greatest amount in all the strains followed by linoleic and palmitic acid. These three fatty acids together accounted for about $94 \%$ of the fatty acids of the virulent strains $\mathrm{Pb} 141$ and $\mathrm{Pb} 168$, up to $84 \%$ of those of the slightly virulent strain $\mathrm{Pb} 9$ and up to $80 \%$ of those of the avirulent strain $\mathrm{Pb} 140$. Both strains $\mathrm{Pb} 9$ and $\mathrm{Pb} 140$ contained a relatively higher proportion of an unidentified fatty acid than the virulent strains Pb141 and Pb168. The peak of the methyl ester of this fatty acid appeared after $\mathrm{C}_{24: 0}$ and its mass spectrum did not conform to any known fatty acid. Besides these major fatty acids, a number of minor ones were also detected, e.g. myristic acid $\left(\mathrm{C}_{14: 0}\right)$, myristoleic acid $\left(\mathrm{C}_{14: 1}\right)$, pentadecanoic acid $\left(\mathrm{C}_{15: 0}\right)$, heptadecanoic acid $\left(\mathrm{C}_{17: 3}\right)$, arachidic acid $\left(\mathrm{C}_{20: 0}\right)$, eicosenoic acid $\left(\mathrm{C}_{20: 1}\right)$, eicosadienoic acid $\left(\mathrm{C}_{20: 2}\right)$, behenic acid $\left(\mathrm{C}_{22: 0}\right)$, docosadienoic acid $\left(\mathrm{C}_{22: 2}\right)$ and lignoceric acid $\left(\mathrm{C}_{24: 0}\right)$.

\section{Polar and neutral lipid composition}

Analysis of the polar and neutral lipid fractions and the further separation of these fractions into individual lipid classes by thin-layer chromatography showed that, regardless of the fungal strain, the neutral lipids were always in greater amount than their corresponding polar fractions (Table 1). The ratio of relative proportions of neutral and polar lipids varied from 3:2 in $\mathrm{Pb} 9$ and $\mathrm{Pb} 141$ to $2: 1$ in $\mathrm{Pbl} 140$ and $\mathrm{Pb} 168$.

The four strains had similar patterns of lipid composition. Phosphatidylcholine (PC) was the dominant phospholipid followed by phosphatidylethanolamine (PE), except in the avirulent strain $\mathrm{Pb} 140$ where cerebroside (CER) was the second highest. The avirulent strain $\mathrm{Pb} 140$ contained less $\mathrm{PC}$ in both the phospholipid and total lipid fractions than the virulent strains. The content of diphosphatidylglycerol (DPG), expressed as a percentage of the total lipid and, in particular, of the phospholipid fraction, was greatest in $\mathrm{Pbl} 68$ followed, in descending order, by $\mathrm{Pb} 141, \mathrm{~Pb} 9$ and $\mathrm{Pb} 140$. The other phospholipids identified were 
phosphatidylinositol (PI), phosphatidylserine (PS) and phosphatidic acid (PA). There was no marked difference in the pattern of their distribution within the four strains. The unidentified lipid was not detected in $\mathrm{Pb} 168$, probably because of its presence in extremely small amounts.

The major fatty acids in the various polar lipid classes of the four strains of $P$. brasiliensis were palmitic acid $\left(C_{16: 0}\right)$, palmitoleic acid $\left(C_{16: 1}\right)$, stearic acid $\left(C_{18: 0}\right)$, oleic acid $\left(C_{18: 1}\right)$ and linoleic acid $\left(\mathrm{C}_{18: 2}\right)$ and together they comprised 82 to $98 \%$ of the total fatty acids of the individual polar lipid classes (Fig. 1). Small amounts of the other fatty acids previously listed were also detected. The avirulent strain $\mathrm{Pb} 140$, and to a lesser extent the slightly virulent strain $\mathrm{Pb}$, contained relatively greater amounts of the unidentified fatty acid in their phospholipid classes than the two virulent strains Pb141 and Pb168. In all four strains PI and PS had a similar fatty acid distribution with palmitic acid being present in greatest amount whereas both PC and PE showed similar fatty acid profiles with oleic acid as the predominant fatty acid. In all four strains DPG was the least saturated lipid with linoleic acid as the predominant fatty acid. The CER of different strains differed slightly with respect to the relative levels of oleic acid and linoleic acid whereas in PA the distribution of fatty acids was random and revealed no pattern.

The separation of neutral lipids into various classes (Table 1) clearly showed that triglycerides represented the most predominant lipid class in all strains. They constituted 25 to $45 \%$ of the total lipid with the greater amount being present in the avirulent $\mathrm{Pb} 140$ and slightly virulent $\mathrm{Pb} 9$ strains [ $36 \mathrm{mg}\left(\mathrm{g}_{\text {dry }} \mathrm{wt}\right)^{-1}$ ] as compared to the virulent strains $\mathrm{Pb} 141$ and $\mathrm{Pb} 168$ [15 to $16 \mathrm{mg}$ (g dry $\mathrm{wt})^{-1}$. Free fatty acids, sterols and sterol esters apparently did not show any preferential distribution in the four strains. Similarly, these classes of neutral lipid did not develop any pattern in the distribution of their fatty acids. However, the triglycerides, diglycerides and monoglycerides of the virulent strains $\mathrm{Pb} 141$ and $\mathrm{Pb} 168$ differed from the avirulent $\mathrm{Pb} 140$ and slightly virulent $\mathrm{Pb} 9$ strains with respect to the percentage of unidentified fatty acid. The latter two strains possessed greater amounts of this acid than of oleic acid, which was the predominant fatty acid of the virulent strains $\mathrm{Pb} 141$ and $\mathrm{Pb} 168$.

\section{DISCUSSION}

The total lipid content of the four strains of $P$. brasiliensis, cultured under identical conditions, varied considerably. However, the quantity of lipid obtained from a particular strain appeared characteristic and showed reasonable agreement between replicate studies. The lipid composition of $P$. brasiliensis was qualitatively similar to other human pathogenic fungi, e.g. H. capsulatum and B. dermatitidis (Domer \& Hamilton, 1971) and C. immitis (Anderes et al., 1973). In all these fungi neutral lipids are the major component of the total lipids and triglycerides are the greatest single lipid class in the extracts. Among phospholipids, phosphatidylcholine and phosphatidylethanolamine are the most prominent fractions.

Paracoccidioides brasiliensis differed from other pathogenic fungi in the lack of any apparent correlation between virulence and the total lipid or phospholipid content of different strains. In four strains of $B$. dermatitidis, Di Salvo \& Denton (1963) observed a positive correlation between total lipid in yeast-phase cells and mouse virulence, though they did not observe a corresponding correlation for phospholipid fractions. Cox \& Best (1972), on the other hand, suggested a possible relationship between phospholipids and virulence in $B$. dermatitidis. Similar results showing a greater amount of total lipid in the arthrospores of the virulent strain of $C$. immitis as compared to the non-virulent mutant were obtained by Anderes et al. (1973). Probably, a higher lipid content protects the microorganism against the host defence mechanisms. This possibility was tested by Anderes et al. (1971) who suggested that exposure of a micro-organism to antimicrobial agents tended to 

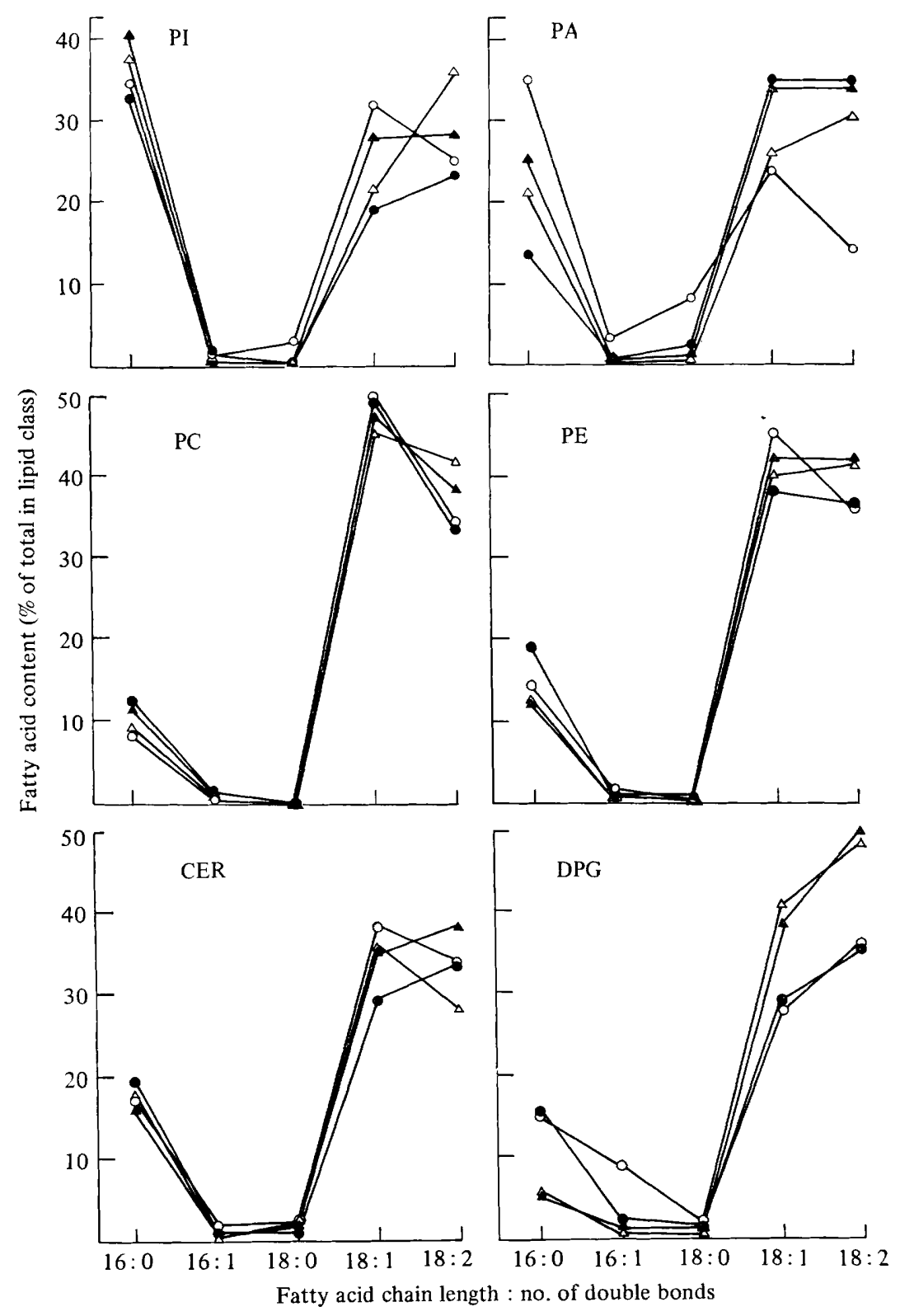

Fig. 1. Content of palmitic $\left(\mathrm{C}_{16: 0}\right)$, palmitoleic $\left(\mathrm{C}_{16: 1}\right)$, stearic $\left(\mathrm{C}_{18: 0}\right)$, oleic $\left(\mathrm{C}_{18: 1}\right)$ and linoleic $\left(\mathrm{C}_{18: 2}\right)$ acids in the polar lipid classes of the four strains of Paracoccidioides brasiliensis: $\mathbf{\Lambda}, \mathrm{Pb} 141$; $\triangle$, Pb168; ๑, Pb140; O, Pb9. Polar lipid classes: PI, phosphatidylinositol; PA, phosphatidic acid; PC, phosphatidylcholine; PE, phosphatidylethanolamine; CER, cerebroside; DPG, diphosphatidylglycerol.

produce a much higher lipid content. Nielsen (1966) examined six isolates of $H$. capsulatum and found that neither the total lipid nor phospholipid showed any correlation with virulence: $50 \%$ or more of the phospholipids were phosphoinositides, and PE was present in much greater concentration than PC. The latter was absent in the less virulent strains. These findings were very different from those of Domer \& Hamilton (1971), who observed higher concentrations of PC than of PE and PI in different strains of H. capsulatum and B. derma- 
titidis. Such discrepancies could be due to differences in cultural conditions, extraction procedures, methods of separation and of identification of lipid classes, all of which could influence the results.

Our data showed that PC was the predominant phospholipid with the concentration in virulent and slightly virulent strains being considerably greater than in the avirulent strain. The four strains of $P$. brasiliensis also contained appreciable amounts of cerebrosides, not reported in other pathogenic fungi. A near relative, sphingolipid, has been reported in $H$. capsulatum (Nielsen, 1966). In B. dermatitidis and $C$. albicans, besides $\mathrm{PC}$ and PE, Peck (1947) reported the presence of an unidentified carbohydrate-containing lipid and stated that this lipid was found mostly in association with pathogenic as opposed to nonpathogenic fungi. It is possible that the unidentified substance was a cerebroside. The biological function of these lipids is not fully understood, but their role in immunological activity and as constituents of cellular membranes is well known.

Most of the literature dealing with lipid analyses in relation to virulence of pathogenic fungi pays little attention to the neutral lipids, even though the latter constitute $60 \%$ or more of the total yield. Analyses of neutral lipids from extracts of $P$. brasiliensis strains revealed six different classes of lipids with triglycerides being the most abundant. The amount of triglycerides was greatest in the avirulent strain and least in the virulent strains. The latter strains also possessed a smaller percentage of an unidentified fatty acid in their triglycerides than the avirulent and slightly virulent strains. Although triglycerides represent the most efficient form of energy storage, their relative amounts depend on the culture conditions and stage of growth. The contribution triglycerides make to the virulence of strains of $P$. brasiliensis remains to be established.

The only indication, if any, of the possible association of phospholipids with virulence was provided by the DPG content of different strains of P. brasiliensis. Diphosphatidylglycerol was the least saturated of the lipids present and contained greater amounts of linoleic acid than of either oleic or palmitic acid. The greatest amount was found in the virulent strains and the least in the avirulent strain. This probably reflects the higher metabolic status of the virulent strains since DPG is generally associated with mitochondria or cellular organelles of high metabolic activity.

There is strong evidence for the participation of lipid intermediates in the synthesis of $\beta$-glucan and cellulose in plants (Hopp et al., 1978). The literature on the role of lipid-like intermediates in fungal cell wall biosynthesis is sparse, but the involvement of a lipid intermediate in $\beta$-glucan biosynthesis has been postulated (Brett \& Northcote, 1975). In a recent review on the biochemistry of the cell wall of $P$. brasiliensis, San-Blas \& San-Blas (1977) have shown a definite correlation between the cell wall composition, especially the $\alpha$-glucan content, and the degree of virulence of a particular strain of $P$. brasiliensis. They have suggested that the constituent macromolecules of the cell wall play an important role in the active protection of the fungus against the defensive mechanisms of the host. It seems pertinent to undertake further investigations on the macromolecular biosynthesis and architecture of the cell wall of $P$. brasiliensis in order to identify those molecules that might be correlated with virulence.

The senior author acknowledges research grants from Consejo Nacional de Investigaciones Cientificas y Tecnologicas (CONICIT), Caracas, Venezuela, and from National Sciences and Engineering Research Council of Canada. 


\section{REFERENCES}

Anderes, E. A., Sandine, W. E. \& Elliker, P. R. (1971). Lipids of antibiotic sensitive and resistant strains of Pseudomonas aeruginosa. Canadian Journal of Microbiology 17, 1357-1365.

Anderes, E. A., Finley, A. A. \& WAlch, H. A. (1973). The lipids of an auxotrophic avirulent mutant of Coccidioides immitis. Sabouraudia 11, 149-157.

BERLINER, M. D. \& ReCA, E. (1966). Vital staining of Histoplasma capsulatum with Janus green B. Sabouraudia 5 26-29.

Brett, C. T. \& NorthCote D. H. (1975). The formation of oligoglucans linked to lipid during synthesis of $\beta$-glucan by characterized membrane fractions isolated from peas. Biochemical Journal 148, 101-117.

CARrol, K. K. (1961). Quantitative estimation of peak areas in gas liquid chromatography. Nature, London 191, 377-378.

Cox, R. A. \& Best, G. K. (1972). Cell wall composition of two strains of Blastomyces dermatitidis exhibiting differences in virulence for mice. Infection and Immunity 5, 449-453.

Deven, J. M. \& Manocha, M. S. (1975). The effect of glutamic acid on the fatty acid and lipid composition of Choanephora cucurbitarum. Canadian Journal of Microbiology 21, 1827-1833.

Di Salvo, A. \& Denton, J. F. (1963). Lipid content of four strains of Blastomyces dermatitidis of different mouse virulence. Journal of Bacteriology 85, 927-931.
Domer, J. E. \& Hamilton, J. G. (1971). The readily extracted lipids of Histoplasma capsulatum and Blastomyces dermatitidis. Biochimica et biophysica acta 231, 465-478.

Folch, J., Lees, M. \& Sloane-Stanley, G. H. (1957). A simple method for the isolation and purification of total lipids from animal tissues. Journal of Biological Chemistry 226, 497-509.

Hopp, H. E., Romero, P. A., Daleo, G. R. \& Pont LezICA, R. (1978). Synthesis of cellulose precursors: the involvement of lipid-linked sugars. European Journal of Biochemistry 84, 561-571.

NiELSEN, H. S., JR. (1966). Variation in lipid content of strains of Histoplasma capsulatum exhibiting different virulence properties for mice. Journal of Bacteriology 91, 273-277.

PECK, R. L. (1947). The lipids of fungi with special references to pathogenic fungi. In Biology of Pathogenic Fungi, pp. 162-188. Edited by W. J. Nickerson. New York: Ronald Press.

SAN-Blas, F. \& CENTENo, S. (1977). Isolation and preliminary characterization of auxotrophic and morphological mutants of the yeastlike form of Paracoccidioides brasiliensis. Journal of Bacterio$\log y$ 129, 138-144.

San-Blas, G. \& San-Blas, F. (1977). Paracoccidioides brasiliensis: cell wall structure and virulence. Mycopathologia 62, 77-86. 